\title{
A multiplex PCR assay for six Aedini species, including Aedes albopictus
}

\author{
Woo Jun Bang ${ }^{1,2}$, Min Hyeok Won ${ }^{1,2}$, Seong Tae Cho ${ }^{1}$, Jihun Ryu ${ }^{1,2}$ and Kwang Shik Choi $i^{1,2,3^{*}}$
}

\begin{abstract}
Background: Mosquitoes, as vectors of various human pathogens, are significant drivers of serious human illness. In particular, those species in the Aedini tribe, which typically transmit dengue virus, Chikungunya fever virus, and Zika virus, are increasing their range because of climate change and international commerce. In order to evaluate the risk of disease transmission, accurate mosquito species identification and monitoring are needed. The goal of this work was to develop a rapid and simple molecular diagnostic method for six morphologically similar Aedini species (Aedes flavopictus, Aedes albopictus, Ochlerotatus koreicus, Ochlerotatus japonicus, Ochlerotatus togoi and Ochlerotatus hatorii) in Korea.
\end{abstract}

Methods: A total of 109 samples were assayed in this study. The internal transcribed spacer 2 (ITS2) regions from all six species were amplified, sequenced and analyzed using Mega 6. Following the identification of regions that were consistently different in terms of sequence between all six species, multiplex primers were designed to amplify these regions to generate species-specific fragments distinguishable by their size.

Results: Uniquely sized fragments were generated in Ae. flavopictus (495 bp), Ae. albopictus (438 bp), Oc. koreicus (361 bp), Oc. togoi (283 bp), Oc. hatorii (220 bp) and Oc. japonicus (160 bp). Pairwise distance analysis showed that the difference was $35.0 \pm 1.5 \%$ between Aedes spp. and Ochlerotatus spp., 17.4 $\pm 0.2 \%$ between Ae. albopictus and Ae. flavopictus and $11.1 \pm 0.3 \%$ between Oc. koreicus and Oc. japonicus.

Conclusions: In this study, a multiplex PCR assay for six species of the Aedini tribe was developed. This assay is more accurate than morphological identification and will be useful for monitoring and controlling these vector mosquitoes.

Keywords: Aedini, Aedes albopictus, Internal transcribed spacer 2, Multiplex PCR assay

\section{Background}

Mosquitoes are vectors of numerous animal and human pathogens, and the threat of mosquito-borne diseases is increasing in parallel with the expansion of the ranges of these mosquito vectors. The expansion of mosquito is driven by climate change and increased introductions into novel territory facilitated by international travel and commerce $[1,2]$. More than 250 million people are

*Correspondence: ksc@knu.ac.kr

1 School of Life Sciences, Kyungpook National University, Biology building 226, Daehak-ro 80, Daegu, Korea

Full list of author information is available at the end of the article exposed to mosquito-borne dengue viruses, and more than 400,000 people die from malaria each year [3].

Among the Aedini tribe, Aedes spp. and Ochlerotatus spp. are known to transmit dengue virus, Chikungunya virus and yellow fever virus, and have been recently shown to be the main vector of Zika virus $[4,5])$. The main species that serve as vectors for these diseases are Aedes aegypti and Aedes albopictus. Notably, the range of Ae. albopictus, which is a potential vector for dengue and Zika virus, has been expanding worldwide since the beginning of the twentieth century as climate change and international transport accelerate. It is currently identified as a major invasive species $[6,7]$. Aedes albopictus is more heat- and stress-tolerant and 
is more widely distributed in Asia than Ae. aegypti [8]. In addition, this species can carry 22 more strains of arboviruses than Ae. aegypti and is likely to be a major vector in areas where Ae aegypti is absent [9-11].

In Korea, 12 species of mosquitoes, including $A e$. albopictus, are known to transmit vector-borne diseases [12]. Every mosquito-borne disease is managed by the Korea Disease Control and Prevention Agency (KDCA) as 'a legal infectious disease' necessitating extra surveillance because of the possibility of being introduced from abroad and exacerbated by climate change [13]. Although there have been no reported cases of these viruses as indigenous to Korea, a mosquito infected with dengue virus was found near the airport in Incheon, Korea in 2019, suggesting that the spread of vector-borne diseases due to introductions and climate change is a real threat [14].

Six species of the Aedini tribe (Ae. albopictus, Aedes flavopictus, Ochlerotatus japonicus, Ochlerotatus koreicus, Ochlerotatus togoi and Ochlerotatus hatorii) found in Korea are difficult to identify and distinguish morphologically. Aedes flavopictus, a potential vector of the dengue virus, was thought to be restricted to Korea and Japan but has recently been found in Europe [15, 16]. Ochlerotatus japonicus has recently spread to North America and Europe and is known to transmit West Nile virus, Chikungunya virus and dengue virus [17-19]. Ochlerotatus koreicus is a common species that lives in urban areas, and it is a vector of Japanese encephalitis and Chikungunya virus [20,21]. Ochlerotatus togoi, which is the main vector of lymphatic filariasis, lives in coastal areas of East Asia and also exists along the coast of North America and South America [22-24]. Ochlerotatus hatorii is known to be distributed in Korea and Japan [25]. Although the latter species is morphologically similar to the other five species, it has rarely been studied ecologically or biologically.

Successful mitigation of these mosquito-borne diseases requires regular monitoring of the range and population density of their mosquito vectors. This monitoring requires rapid and accurate methods to identify mosquito species. However, morphological identification is difficult, especially if the scales or legs which are used in identification are lost or missing from the specimens $[25,26]$. Consequently, the development of a rapid and accurate identification method would be extremely useful. In this study, we describe the development of a new molecular diagnostic method for these six mosquito species using the internal transcribed spacer 2 (ITS2) of the ribosomal RNA (rRNA) region.

\section{Methods}

\section{Mosquito sample collection and information}

From August to September 2019, adults and larval mosquitoes were collected from mosquito habitats in five regions of Korea (Chiak mountain, Yongmun mountain, Daedeok mountain, Bibong mountain and Bomokpo port) (Fig. 1). Aedes. flavopictus adults $(n=20)$ were collected using BG-sentinel $^{\mathrm{TM}}$ (BGS) traps (Biogents, Regensburg, Germany) containing lactic acid and dry ice and then morphologically identified $[25,26]$. Larvae of the other five species were collected from water pools around streams and reared to adults in the insectary. Reared adults were identified using known taxonomy keys $[25,26]$. Information on the mosquito species and number of specimens collected according to collection site is provided in Table 1.

\section{Sequence determination of the ITS2 region of the six Aedini species}

DNA was extracted from each specimen using the AccuPrep ${ }^{\circledR}$ DNA Extraction Kit (K3032; Bioneer Corp., Daejeon, South Korea). Universal primers (forward primer: 5'-AGG ACA CAT GAA CAC CCA CA-3')/reverse primer: 5'-CTC GCA GCT ACT CAG GGA AT-3') were designed from sequences registered in GenBank with the following accession numbers: Ae. flavopictus-AF353524; Ae. albopictus-MN062758; Oc. koreicus-KF471622; Oc. togoi-EU980394; and Oc. japonicus-KF471614. The sequence of the ITS2 region of Oc. hatorii was not available when this study was conducted, and so the sequence of the phylogenetically close Oc. togoi was used instead [27]. Although four samples for each species were sequenced, one sequence per species was deposited in GenBank due to the absence of within-species variation. The analyzed sequence data were deposited in GenBank under the following accession numbers: MT992619 (Ae. albopictus), MW040082 (Ae. flavopictus), MW046043 (Oc. koreicus), MW046046 (Oc. japonicus), MW046045 (Oc. hatorii) and MW046044 (Oc. togoi).

Each individual reaction mixture (total volume $25 \mu \mathrm{l}$ ) contained $0.4 \mu \mathrm{M}$ of each primer, $1 \times$ PCR buffer, $0.2 \mathrm{mM}$ of each dNTP, $1.0 \mathrm{mM} \mathrm{MgCl}_{2}$ and $0.5 \mathrm{U}$ of Taq DNA polymerase (R001AM; TaKaRa Bio Inc., Kusatsu, Shiga, Japan), with $1.0 \mu \mathrm{l}$ of the genomic DNA extracted from an individual specimen. Amplification was conducted on a Thermal Cycler Dice system (TP350; TaKaRa) as follows: $94{ }^{\circ} \mathrm{C}, 5 \mathrm{~min}$; then $94{ }^{\circ} \mathrm{C} / 30 \mathrm{~s}, 55{ }^{\circ} \mathrm{C}, 30 \mathrm{~s}, 72{ }^{\circ} \mathrm{C} / 30$ $\mathrm{s}$ for 35 cycles; with a final extension at $72{ }^{\circ} \mathrm{C}$ for $10 \mathrm{~min}$. PCR products were visualized in $1.5 \%$ (wt/vol) agarose gels stained with ethidium bromide (VWR Life Science, Radnor, PA, USA), and then sequenced in both directions by Macrogen Inc. (Seoul, Korea). Sequences were aligned 


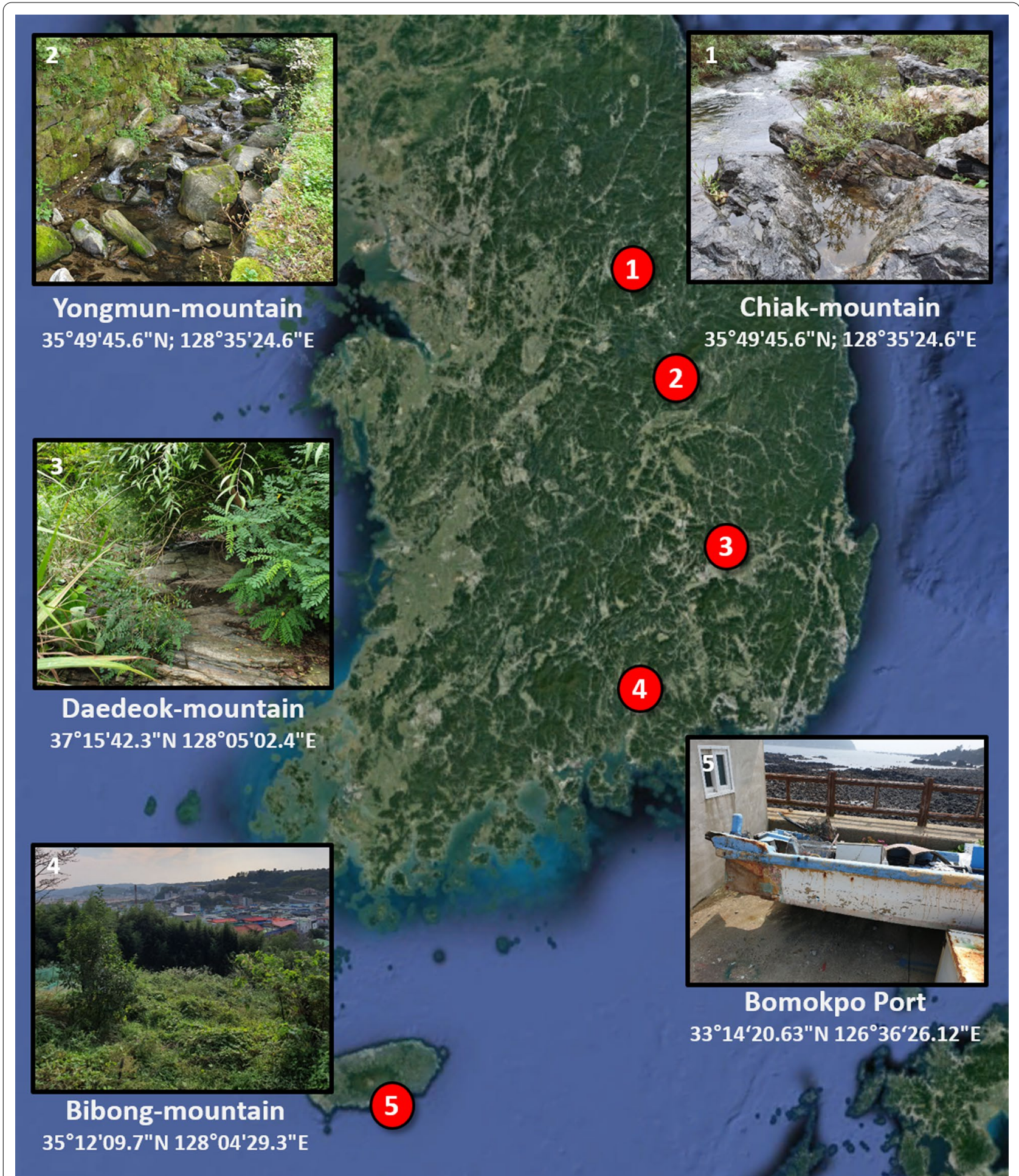

Fig. 1 Collection sites of the six Aedini species in Korea. The numbers in red circles indicate the following collection locations: 1 Chiak mountain, 2 Yongmun mountain, 3 Daedeok mountain, 4 Bibong mountain, 5 Bomokpo port. The background map image was obtained from Google Earth Pro version 7.3.3.7786 (Accessed 7 Dec 2020) 
Table 1 Mosquito species and number of specimens collected in each collection site in Korea

\begin{tabular}{|c|c|c|c|c|c|c|c|}
\hline \multirow[t]{2}{*}{ Specimens $(n)$} & \multirow[t]{2}{*}{ Species } & \multicolumn{5}{|l|}{ Collection sites } & \multirow[t]{2}{*}{ Total $(n)$} \\
\hline & & Chiak mountain & $\begin{array}{l}\text { Yongmun } \\
\text { mountain }\end{array}$ & $\begin{array}{l}\text { Daedeok } \\
\text { mountain }\end{array}$ & $\begin{array}{l}\text { Bibong } \\
\text { mountain }\end{array}$ & Bomokpo port & \\
\hline Collected adults & Aedes flavopictus & & 20 & & & & 20 \\
\hline \multirow[t]{5}{*}{ Reared adults } & Aedes albopictus & 5 & & 7 & 12 & & 24 \\
\hline & Ochlerotatus koreicus & 4 & & 4 & 12 & & 20 \\
\hline & Ochlerotatus japonicus & 2 & & 2 & 1 & & 5 \\
\hline & Ochlerotatus togoi & & & & & 20 & 20 \\
\hline & Ochlerotatus hatorii & 20 & & & & & 20 \\
\hline
\end{tabular}

and analyzed using the Basic Local Alignment Search Tool (BLAST) and Bioedit v7.2.6.1 [28, 29].

\section{Multiplex PCR assay for the six Aedini species}

Six multiplex primer sets consisting of the aforementioned universal forward primer paired with species-specific reverse primers from the ITS2 region were designed (Fig. 2). The multiplex PCR was conducted in a $25-\mu \mathrm{l}$ reaction volume with $0.4 \mu \mathrm{M}$ of each primer (Table 2), $1 \times$ PCR buffer, $0.2 \mathrm{mM}$ of each dNTP, $1.0 \mathrm{mM} \mathrm{MgCl} 2,0.5 \mathrm{U}$ of Taq DNA polymerase (R001AM; TaKaRa Bio Inc.) and $1.0 \mu \mathrm{l}$ of genomic DNA of an individual specimen. The PCR cycling conditions were: $94{ }^{\circ} \mathrm{C}, 5 \mathrm{~min}$; then $94{ }^{\circ} \mathrm{C} / 30$ s, $56{ }^{\circ} \mathrm{C} / 30 \mathrm{~s}, 72{ }^{\circ} \mathrm{C} / 30 \mathrm{~s}$ for 35 cycles; with a final extension step at $72{ }^{\circ} \mathrm{C}$ for $5 \mathrm{~min}$. The products were visualized in $2.0 \%(\mathrm{wt} / \mathrm{vol})$ agarose gels with ethidium bromide (VWR Life Science) and sequenced as described above.

\section{Phylogenetic analysis of the six Aedini species}

The phylogenetic analysis was performed using the neighbor-joining method under the Kimura 2-parameter model. MEGA software version 6 [30] was used to verify phylogenetic relationships and compare these with the results of morphological identification. Bootstrapping based on the ITS2 sequence data was conducted with 1000 replicates, and genetic diversity between the species was compared using pairwise distances.

\section{Results and discussion}

\section{Comparison of ITS2 sequence and multiplex PCR results}

In total, 109 samples of DNA extracted from individual mosquitoes were used for the study (20 Ae. flavopictus samples, 24 Ae. albopictus samples, 5 Oc. japonicus samples, 20 Oc. koreicus samples, 20 Oc. hatorii samples and 20 Oc. togoi samples).

The lengths of the sequenced fragments of the ITS2 regions of the six Aedini species were 580 bp (Ae. flavopictus), $576 \mathrm{bp}$ (Ae. albopictus), 450 bp (Oc. koreicus), $451 \mathrm{bp}$ (Oc. togoi), $406 \mathrm{bp}$ (Oc. hatorii) and $456 \mathrm{bp}$ (Oc. japonicus). The sequence of each fragment was aligned (using BLAST) with the existing sequence registered in GenBank (Ae. Albopictus: accession MN062758 Palestine, MF623839, KU497619 China; Ae. flavopictus: AF353524, AF353551, AF353553 Japan; Oc. koreicus: MK765859 Hungary, JF430391, KF471630 Belgium; Oc. japonicus: KF471619 Austria, FJ641870 Belgium, GU121103 USA; Oc. togoi: EU980394 Korea) and used to check the binding sites for the universal and specific reverse primers.

A gel showing the results of the multiplex analysis of DNA from each species is shown in Fig. 3 (Ae.flavopictus [495 bp], Ae. albopictus [438 bp], Oc. korecus [361 bp], Oc. togoi [283 bp], Oc. hatorii [220 bp], Oc. japonicus [160 bp]). The results of molecular analysis were consistent with those of the morphological study.

\section{Results of the phylogenetic analysis using MEGA 6}

The ITS2 results of the six Aedini species sequenced in this study (accessions MT992619, MW040082, MW046043, MW046046, MW046045, MW046044) and other ITS2 sequences deposited in GenBank from other species in the Aedini tribe (accessions KF471630, MK765859, JF430391, FJ641870, KF471619, GU121103, EU980394, MN062758, KU497619, MF623839, AF353524, AF353553, and AF353551) were analyzed to determine phylogenetic relatedness between the six species as well as within the six species (Fig. 4).

Aedes albopictus and Ae. flavopictus, which are morphologically similar, were more closely related with each other than with the other Aedini species, as were Oc. koreicus and Oc. japonicus. The phylogenetic tree was clearly divided into Aedes spp. and Ochlerotatus spp. while Oc. hatorii and Oc. togoi were only distantly related to the other Ochlerotatus spp. A pairwise analysis of genetic distances using the Kimura 2-parameter calculation and the interspecies ITS2 region showed a $35.0 \pm 1.5 \%$ difference between Aedes spp. and Ochlerotatus spp., a $17.4 \pm 0.2 \%$ difference between Ae. albopictus and Ae. flavopictus and a $11.1 \pm 0.3 \%$ difference between 


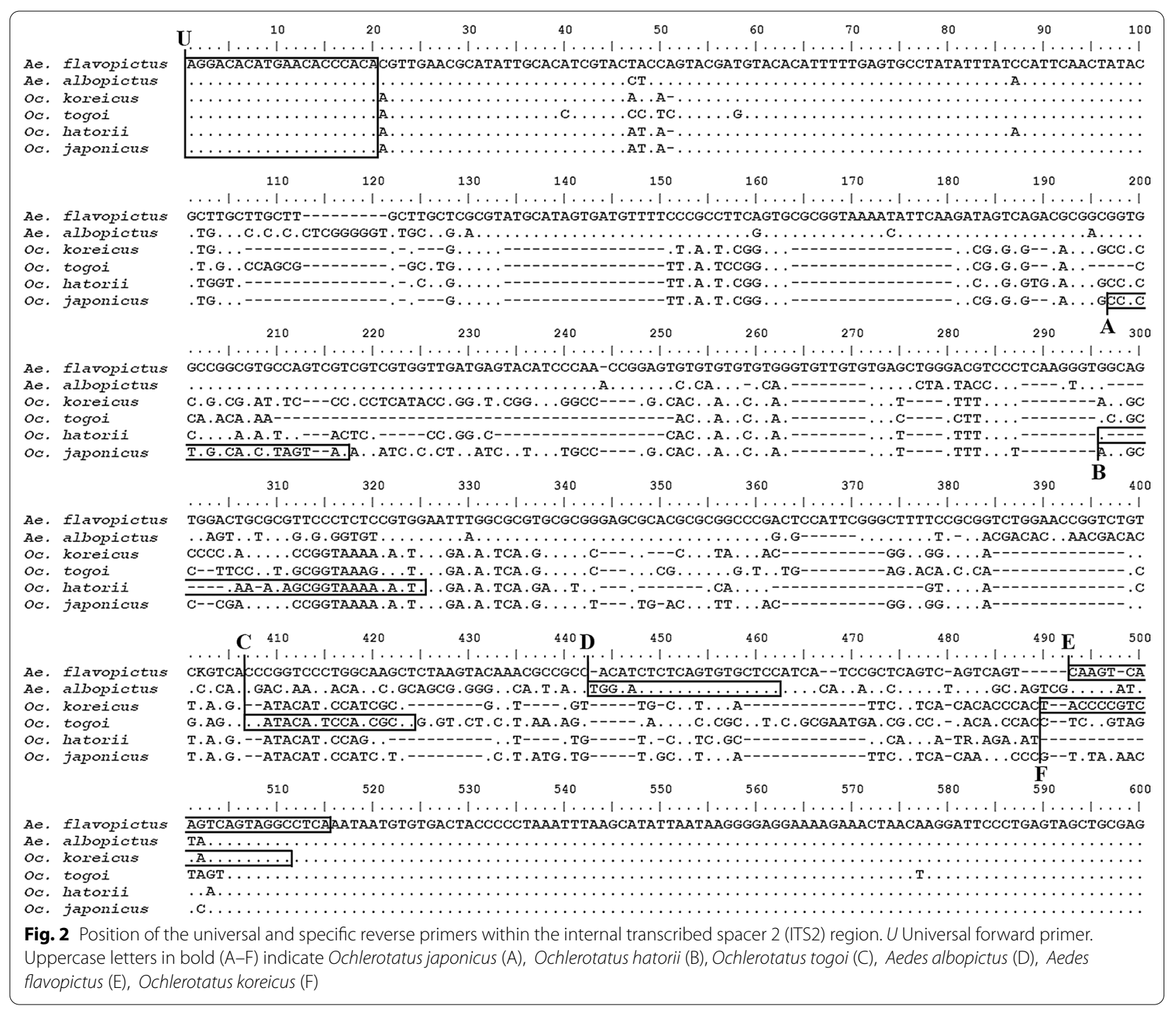

Table 2 Universal forward primer sequences and specific reverse primer sequences for the six species of mosquitoes assayed in this study

\begin{tabular}{llll}
\hline Species & Forward primer $\left(5^{\prime} \rightarrow 3^{\prime}\right)$ & Reverse primer $\left(5^{\prime} \rightarrow 3^{\prime}\right)$ & $\begin{array}{l}\text { } \\
\text { Product } \\
\text { length } \\
(\mathrm{bp})\end{array}$ \\
\hline Aedes flavopictus & AGGACACATGAACACCCACA & TGAGGCCTACTGACTTGACTTG & 495 \\
Aedes albopictus & & GGAGCACACTGAGAGTTCCA & 438 \\
Ochlerotatus koreicus & GCCTACTGATTGACGGGTA & 361 \\
Ochlerotatus togoi & AGGCGGTGAGTGTATGG & 283 \\
Ochlerotatus hatorii & CAATGTTTACCGCTGTTGC & 220 \\
Ochlerotatusjaponicus & TATACTACGCTGCCGAGG & 160 \\
\hline
\end{tabular}

Oc. koreicus and Oc. japonicus. The analysis of intraspecies variation showed: Ae. albopictus $0.44 \pm 0.2 \%$, Ae. flavopictus $0.41 \pm 0.3 \%$, Oc. koreicus $1.11 \pm 0.7 \%$, Oc. japonicus $0.84 \pm 0.4 \%$ and Oc. togoi $0.67 \%$ (Additional file 1: Table $\mathrm{S} 1$ ). In addition, the results showed little variation between countries within the species. This is the 


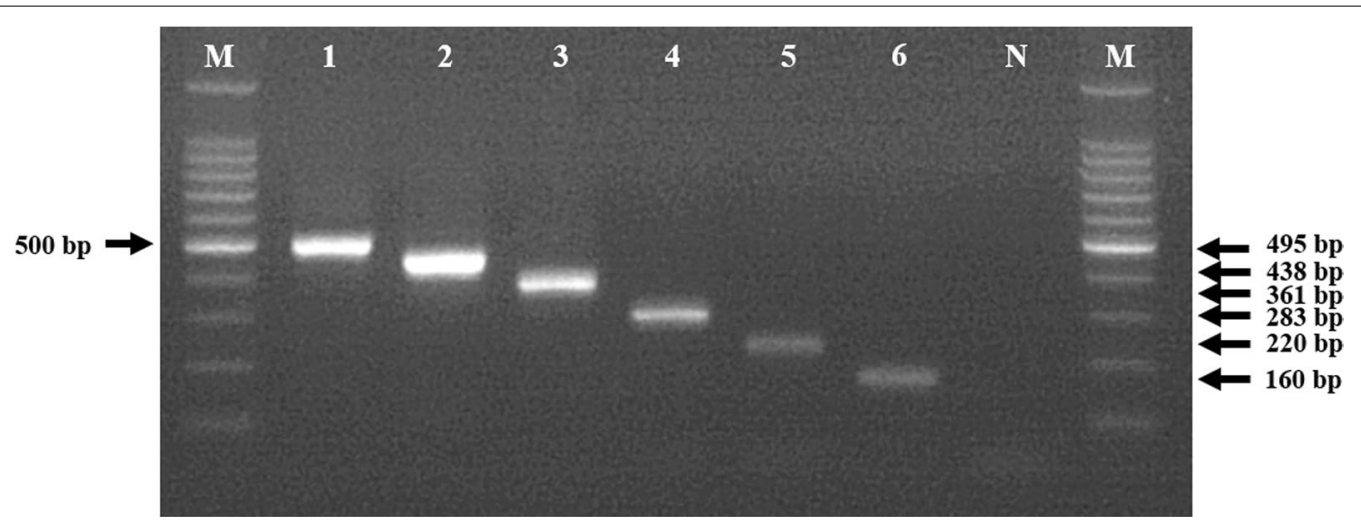

Fig. 3 Example of the results of the multiplex PCR assay for six Aedini species. Lanes: M 100-bp molecular marker, 1 Aedes flavopictus (495 bp), 2 Aedes albopictus (438 bp), 3 Ochlerotatus koreicus (361 bp); 4 Ochlerotatus togoi (283 bp), 5 Ochlerotatus hatorii (220 bp), 6 Ochlerotatus japonicus (160 bp)

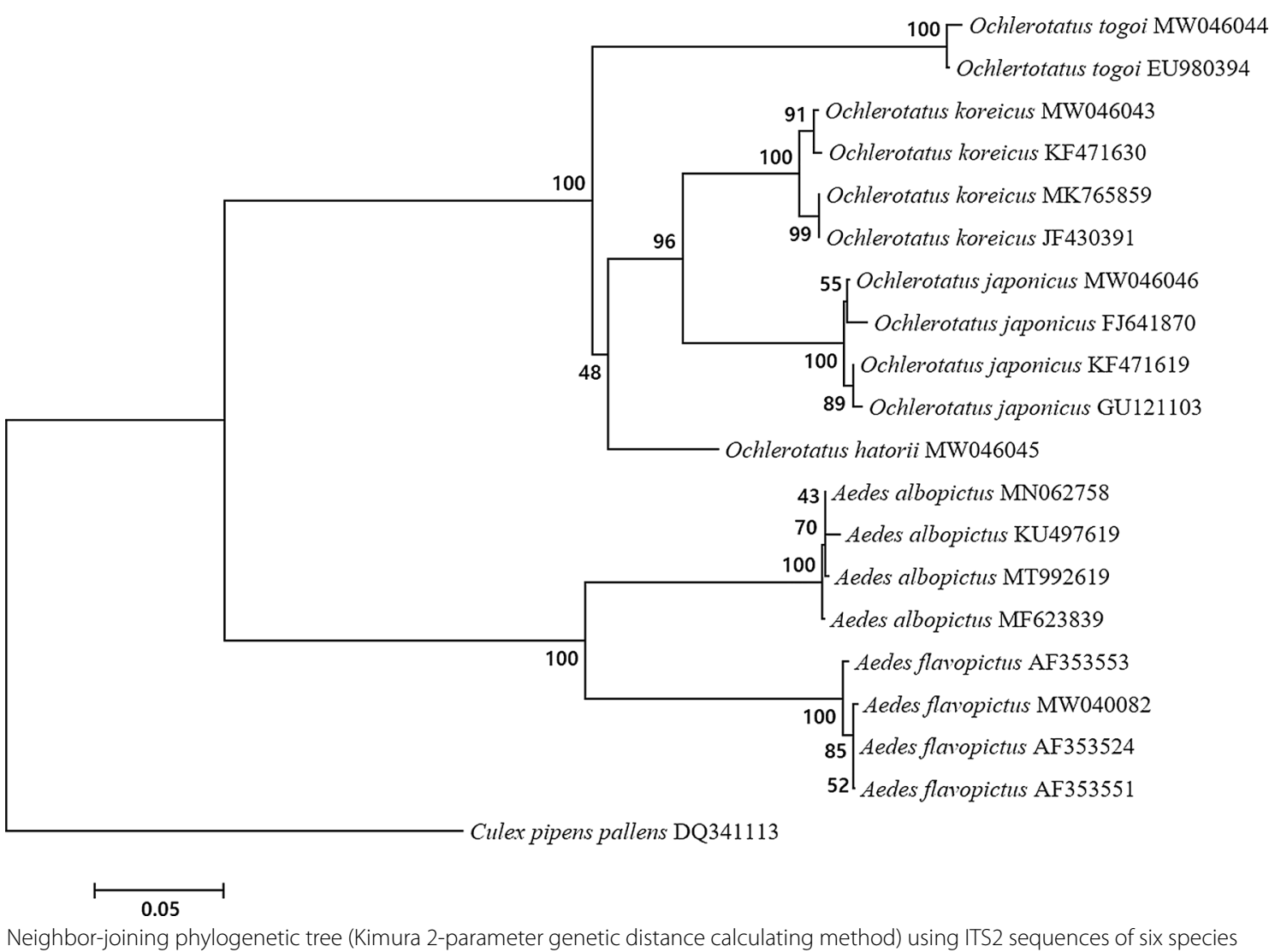

first report of the results of a phylogenetic analysis of the six species. Although the species are morphologically indistinguishable, the phylogenetic relationship between six species of Aedini tribe as well as between the genera was confirmed by this analysis. There was no discordance between morphological identification and the results of the molecular and phylogenetic analysis for the six Aedini species.

\section{Application of multiplex PCR molecular diagnostic method} All of the six Aedini species included in this study are very similar morphologically and are identified 
morphologically by fine differences in the leg, scales, scutum and scutellum $[25,26]$. However, the very tediousness of the identification process based on accurate determination of morphological characters and the very real possibility that legs and scales may be lost during collection or storage results in a substantial misidentification rate. The multiplex PCR assay using the ITS2 region which we developed can reduce this misidentification rate and is simple-requiring only PCR followed by electrophoresis.

The ITS2 region is located in between the $5.8 \mathrm{~S}$ and $28 \mathrm{~S}$ subunits which are conservative with little withinspecies variation. It is a non-coding region and shows a rapid divergence between species. Also, it is easy to design primers at the conservative regions $(5.8 \mathrm{~S}$ and $28 \mathrm{~S}$ ) and multiple copies with fragments of $<1 \mathrm{~kb}$ are present, which is favorable for amplification [31, 32]. Given these advantages, the ITS2 region has been used to identify closely related or morphologically indistinguishable species [33, 34]. A multiplex PCR assay for Anopheles spp., which transmit malaria, has also been developed and is being used to monitor certain vector species of Anopheles spp. [35-38].

The multiplex PCR assay we developed for Aedini species enables a simple and accurate identification and monitoring of species of mosquitoes that carry flaviviruses such as dengue virus, yellow fever virus and Zika virus. Five of the species analyzed here, the exception being Oc. hatorii, which is not known to transmit disease, have the ability to transmit pathogens and are currently increasing their respective distribution range. Aedes albopictus, which is an endemic species in Asia, has spread into other countries due to the increased trading of waste tires globally $[39,40]$. It has also spread to Africa, the Americas and Europe, thereby increasing the probability of infection in these regions [41-43]. Aedes flavopictus, which is also an endemic species in East Asia, was first reported in Europe in 2019 [16], and Oc. japonicus was reported first in North America in the late 1990s [44, 45] and in Europe in 2002 [46, 47]. Ochlerotatus koreicus was recently reported in Belguim in 2008 and in Italy in 2011 [48, 49], and is considered to be a major invasive species together with $A e$. albopictus in Europe [50]. Ochlerotatus togoi, which is endemic species in East Asia and Southeast Asia, was first detected in North America in 1980 [51, 52]. The multiplex PCR assay described here would be a useful tool for monitoring these mosquito vectors in Korea as well as in countries where they were already spread or have the possibility to invade. The data provided by consistent and accurate monitoring of mosquito populations through this method can potentially be used to guide national public health measures, such as quarantine, and thus help prevent the spread of mosquitoborne diseases.

\section{Conclusions}

In this study, a multiplex PCR assay was developed to identify six Aedini species which can transmit various diseases in Korea. This assay provides a simple and accurate molecular identification tool for these six species, which are difficult to identify morphologically. These species are expected to spread globally due to climate change and increasing international trade. This tool will, therefore, be useful for control of the vectors for several infectious diseases.

\section{Abbreviations}

BLAST: Basic Local Alignment Search Tool; ITS2: Internal transcribed spacer 2; KDCA: Korea Disease Control and Prevention Agency; rRNA: Ribosomal RNA.

\section{Supplementary Information}

The online version contains supplementary material available at https://doi. org/10.1186/s13071-021-04871-7.

Additional file 1: Table S1. An analysis of pairwise distances using the Kimura 2-parameter calculation for six Aedini species.

\section{Acknowledgements}

The authors thank the Basic Science Research Program of the National Research Foundation of Korea (NRF), Korean Ministry of Education, for funding this research (NRF-2020R1I1A2066186).

\section{Authors' contributions}

WJB designed the study, developed the new multiplex PCR assay method for the six Aedini species and drafted the manuscript. MHW and STC assisted with collecting mosquitoes and identifying mosquito species. JR designed the study with WJB, assisted with the analysis of the data and helped draft the manuscript. KSC revised and improved the manuscript. All authors read and approved the final manuscript.

\section{Funding}

This research was supported by Basic Science Research Program through the National Research Foundation of Korea (NRF) funded by the Ministry of Education (2020R111A2066186).

\section{Availability of data and materials}

The datasets generated during the current study are included within the article. Sequences used in this study are deposited in the GenBank database under the accession numbers MT992619, MW040082, MW046043, MW046044, MW046045 and MW046046.

\section{Declarations}

Ethics approval and consent to participate Not applicable.

Consent for publication

Not applicable.

Competing interests

The authors declare that they have no competing interests. 


\section{Author details}

${ }^{1}$ School of Life Sciences, Kyungpook National University, Biology building 226, Daehak-ro 80, Daegu, Korea. ${ }^{2}$ Research Institute for Dokdo and Ulleungdo Island, Kyungpook National University, Daegu, Korea. ${ }^{3}$ Research Institute for Phylogenomics and Evolution, Kyungpook National University, Daegu, Korea.

Received: 11 December 2020 Accepted: 5 July 2021

Published online: 28 July 2021

\section{References}

1. Reiter P. Climate change and mosquito-borne disease. Environ Int. 2001:109:141-61.

2. Tatem AJ, Huang Z, Das A, Qi Q, Roth J, Qiu Y. Air travel and vector-borne disease movement. Parasitology. 2012;139:1816-30.

3. World Health Organization (WHO). Vector-borne diseases. Geneva: WHO. 2020. https:/www.who.int/en/news-room/fact-sheets/detail/vectorborne-diseases. Accessed 7 Dec 2020.

4. Bhatt S, Gething PW, Brady OJ, Messina JP, Farlow AW, Moyes CL, et al. The global distribution and burden of dengue. Nature. 2013;496:504-7.

5. Attaway DF, Waters NM, Geraghty EM, Jacobsen KH. Zika virus: Endemic and epidemic ranges of Aedes mosquito transmission. J Infect Public Health. 2017;10:120-3.

6. Benedict MQ, Levine RS, Hawley WA, Lounibos LP. Spread of the tiger. Vector Borne Zoonotic Dis. 2007;7:76-85.

7. Invasive Species Specialist Group (ISSG). Global Invasive Species Database-Aedes albopictus. The Invasive Species Specialist Group. 2009. http://www.issg.org/database/species/ecology.asp?si=109\&fr=1\&sts= sss\&lang=EN. Accessed 7 Dec 2020.

8. Lwande OW, Obanda V, Lindström A, Ahlm C, Evander M, Näslund J, et al. Globe-trotting Aedes aegypti and Aedes albopictus: risk factors for arbovirus pandemics. Vector-Borne Zoonotic Dis. 2020;20:71-81.

9. Mitchell C. Geographic spread of Aedes albopictus and potential for involvement in arbovirus cycles in the Mediterranean basin. J Vector Ecol. 1995:20:44-58.

10. Gratz NG. Critical review of the vector status of Aedes albopictus. Med Vet Entomol. 2004;18:215-27.

11. Medlock JM, Hansford KM, Versteirt V, Cull B, Kampen H, Fontenille D, et al. An entomological review of invasive mosquitoes in Europe. Bull Entomol Res. 2015;105:637-63.

12. Lee DK. Ecological characteristics and current status of infectious disease vectors in South Korea. J Korean Med Assoc. 2017;60:458-67.

13. Korea Disease Control and Prevention Agency (KDCA). Infectious Disease Portal. Cheongju: KDCA. 2020. http://www.kdca.go.kr/npt/biz/npp/ nppMain.do. Accessed 7 Dec 2020.

14. Korea Disease Control and Prevention Agency (KDCA). Dengue virus detection through mosquito surveillance in Incheon, Republic of Korea. Cheongju: KDCA. 2019; http://www.kdca.go.kr/board.es?mid=a2050 1000000\&bid=0015\&act=view\&list_no=364502. Accessed 7 Dec 2020.

15. Srisawat R, Phanitchat T, Komalamisra N, Tamori N, Runtuwene L, Noguchi K, et al. Susceptibility of Aedes flavopictus miyarai and Aedes galloisi mosquito species in Japan to dengue type 2 virus. Asian Pac J Trop Biomed. 2016;6:446-50.

16. Ibáñez-Justicia A, van de Vossenberg B, van den Biggelaar R, Voogd J, et al. Detection of Aedes flavopictus (Yamada, 1921), Netherlands, June 2019. Euro Surveill. 2019;24(30):1900433.

17. Turell MJ, O'Guinn ML, Dohm DJ, Jones JW. Vector competence of North American mosquitoes (Diptera: Culicidae) for West Nile virus. J Med Entomol. 2001;38:130-4.

18. Schaffner F, Vazeille M, Kaufmann C, Failloux A-B, Mathis A. Vector competence of Aedes japonicus for chikungunya and dengue viruses. J Eur Mosq Control Assoc. 2011;29:141-2.

19. Koban MB, Kampen H, Scheuch DE, et al. The Asian bush mosquito Aedes japonicus japonicus (Diptera: Culicidae) in Europe, 17 years after its first detection, with a focus on monitoring methods. Parasites Vectors. 2019;12:109.

20. Shestakov VI, Mikheeva AIK. Study of vectors of Japanese encephalitis in the Maritime Territory. Med Parazitol. 1966;35(5):545-50.
21. Ciocchetta S, Prow NA, Darbro JM, Frentiu FD, Savino S, Montarsi F, et al The new European invader Aedes (Finlaya) koreicus: a potential vector of chikungunya virus. Pathog Glob Health. 2018;112:107-14

22. Cheun HI, Cho SH, Lee HI, Shin EH, Lee JS, Kim TS, et al. Seasonal prevalence of mosquitoes, including vectors of Brugian filariasis, in Southern Islands of the Republic of Korea. Korean J Parasitol. 2011;49:59-64.

23. Wada Y. Vector mosquitoes of filariasis in Japan. Trop Med Health. 2011;39:39-45

24. Peach DAH, Almond M, Pol JC. Modeled distributions of Aedes japonicus japonicus and Aedes togoi (Diptera: Culicidae) in the United States, Canada, and northern Latin America. J Vector Ecol. 2019:44(1):119-29.

25. Tanaka K, Mizusawa K, Saugstad ES, et al. A revision of the adult and larval mosquitoes of Japan (including the Ryukyu Archipelago and the Ogasawara islands) and Korea (Diptera: Culicidae). Contrib Am Entomol Inst. 1979;16:1.

26. Ree H-I. Taxonomic review and revised keys of the Korean mosquitoes (Diptera: Culicidae). Entomol Res. 2003;33:39-52.

27. Soghigian J, Andreadis TG, Livdahl TP. From ground pools to treeholes: convergent evolution of habitat and phenotype in Aedes mosquitoes. BMC Evol Biol. 2017;17:1-13.

28. Johnson M, Zaretskaya I, Raytselis Y, Merezhuk Y, et al. NCBI BLAST: a better web interface. Nucleic Acids Res. 2008;36:5-9.

29. Hall TA. BioEdit: A user-friendly biological sequence alignment editor and analysis program for Windows 95/98/NT. Nucleic Acids Symp Ser. 1999:41:95-8.

30. Tamura K, Stecher G, Peterson D, Filipski A, et al. MEGA6: Molecular Evolutionary Genetics Analysis version 6.0. Mol Biol Evol. 2013:30(12):2725-9.

31. Beckingham K. Insect rDNA. In: Busch H, Rothblum L, editors. The cell nucleus. New York: Academic Press; 1982. p. 205-63.

32. Baldwin BG, Sanderson MJ, Porter JM, Martin F, Campbell CS, Donoghue MJ, et al. The ITS region of nuclear ribosomal DNA: a valuable source of evidence on angiosperm phylogeny source. Ann Missouri Bot Gard 1995:82:247-77.

33. Collins FH, Mendez MA, Rasmussen MO, Mehaffey PC, Besansky NJ, Finnerty $\mathrm{V}$. A ribosomal RNA gene probe differentiates member species of the Anopheles gambiae complex. Am J Trop Med Hyg. 1987;37:37-41.

34. Collins FH, Paskewitz SM. A review of the use of ribosomal DNA (rDNA) to differentiate among cryptic Anopheles species. Insect Mol Biol. 1996:5:1-9.

35. Scott JA, Brogdon WG, Collins FH. Identification of single specimens of the Anopheles gambiae complex by the polymerase chain reaction. Am J Trop Med Hyg. 1993:49(4):520-9.

36. Fanello C, Santolamazza F, Della TA. Simultaneous identification of species and molecular forms of the Anopheles gambiae complex by PCR-RFLP. Med Vet Entomol. 2002;16(4):461-4.

37. Joshi D, Park MH, Saeung A, Choochote W, Min GS. Multiplex assay to identify Korean vectors of malaria. Mol Ecol Resour. 2010;10:748-50.

38. Brosseau L, Udom C, Sukkanon C, Chareonviriyaphap T, Bangs MJ, Saeung A, et al. A multiplex PCR assay for the identification of five species of the Anopheles barbirostris complex in Thailand. Parasites Vectors. 2019;12:223.

39. Reinert $P$, Sprenger $D$. The used tire trade: a mechanism for the worldwide dispersal of container breeding mosquitoes. J Am Mosq Control Assoc. 1987:3(3):494-501.

40. Craven RB, Eliason DA, Francy DB, Reiter P, Campos EG, Jakob WL, et al. Importance of Aedes albopictus and other exotic mosquito species into the United States in used tires from Asia. J Am Mosq Control Assoc. 1988:4(2):138-42.

41. Gubler DJ. Aedes albopictus in Africa. Lancet Infect Dis. 2003:3(12):751-2.

42. Dalla Pozza G, Majori G. First record of Aedes albopictus establishment in Italy. J Am Mosq Control Assoc. 1992;8(3):318-20.

43. Rodhain F. Problems posed by the spread of Aedes albopictus. Bull Soc Pathol Exot. 1996;89(2):137-40.

44. Peyton EL, Campbell SR, Candeletti TM, Romanowski M, Crans WJ. Aedes (Finlaya) japonicus japonicus (Theobald), a new introduction into the United States. J Am Mosq Control Assoc. 1999;15:238-41.

45. Falco RC, Daniels TJ, Slamecka MC. Prevalence and distribution of Ochlerotatus japonicus (Diptera: Culicidae) in two countries in Southern New York State. J Med Entomol. 2002;39:920-5.

46. Schaffner F, Kaufmann C, Hegglin D, Mathis A. The invasive mosquito Aedes japonicus in central Europe. Med Vet Entomol. 2009;23:448-51. 
47. Montarsi F, Martini S, Michelutti A, Da Rold G, Mazzucato M, Qualizza D, et al. The invasive mosquito Aedes japonicus japonicus is spreading in northeastern Italy. Parasites Vectors. 2019;12:1-8.

48. Capelli G, Drago A, Martini S, Montarsi F, Soppelsa M, Delai N, et al. First report in Italy of the exotic mosquito species Aedes (Finlaya) koreicus, a potential vector of arboviruses and filariae. Parasites Vectors. 2011;4:1-5.

49. Versteirt V, Pecor JE, Fonseca DM, Coosemans M, Van Bortel W. Confirmation of Aedes koreicus (Diptera:Culicidae) in Belgium and description of morphological differences between Korean and Belgian specimens validated by molecular identification. Zootaxa. 2012;32:21-32.

50. Marcantonio M, Metz M, Baldacchino F, Arnoldi D, Montarsi F, Capelli G, et al. First assessment of potential distribution and dispersal capacity of the emerging invasive mosquito Aedes koreicus in Northeast Italy. Parasites Vectors. 2016;9:1-19.

51. Sota T, Belton P, Tseng M, Sen YH, Mogi M. Phylogeography of the coastal mosquito Aedes togoi across climatic zones: Testing an anthropogenic dispersal hypothesis. PLoS ONE. 2015;10:1-13.

52. Belton P. The first record of Aedes togoi (Theo.) in the United Statesaboriginal or ferry passenger? Mosq News. 1980;40:624-6.

\section{Publisher's Note}

Springer Nature remains neutral with regard to jurisdictional claims in published maps and institutional affiliations.
Ready to submit your research? Choose BMC and benefit from:

- fast, convenient online submission

- thorough peer review by experienced researchers in your field

- rapid publication on acceptance

- support for research data, including large and complex data types

- gold Open Access which fosters wider collaboration and increased citations

- maximum visibility for your research: over $100 \mathrm{M}$ website views per year

At BMC, research is always in progress.

Learn more biomedcentral.com/submissions 